
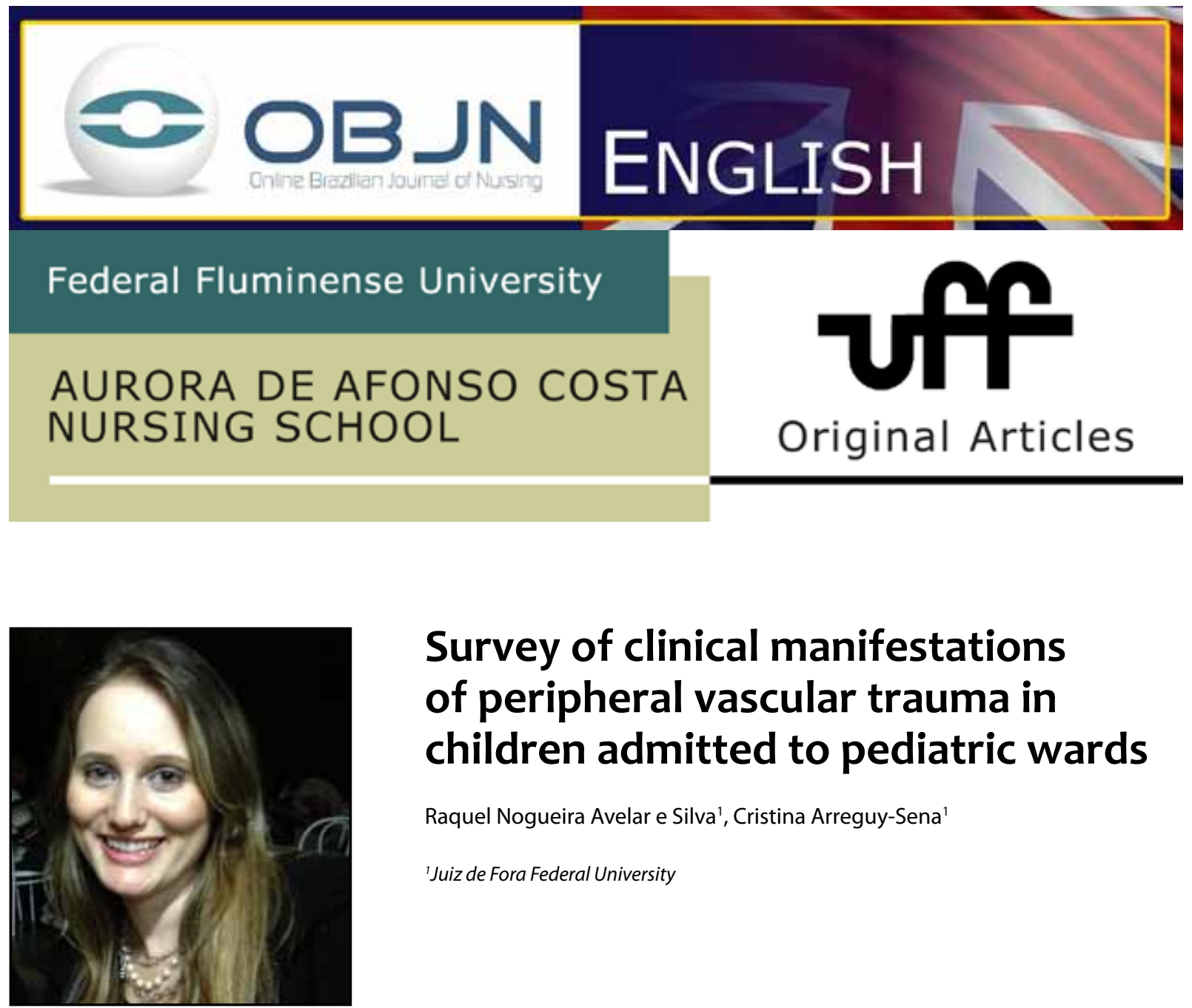

\title{
Survey of clinical manifestations of peripheral vascular trauma in children admitted to pediatric wards
}

Raquel Nogueira Avelar e Silva', Cristina Arreguy-Sena'

'Juiz de Fora Federal University

\begin{abstract}
Aim: To analyze the clinical evidence for a diagnosis of "peripheral vascular trauma" based on occurrence and type, in children between six months and twelve years old. Method: Survey of peripheral venous punctures performed in children having a first puncture on that site. Daily clinical evaluations were performed on the puncture site and adjacent areas at intervals, commencing within 24 hours following the puncture and continuing until the resolution of the trauma, or the patient's discharge, excluding any subsequent punctures. Results: From the 338 punctures observed, 53.3\% presented with at least one clinical manifestation of trauma, characterized by: pain (30.1\%), change in the skin color (18.6\%), skin integrity $(47.7 \%)$, functional capacity (6.2\%) or local temperature (14.2\%).

Discussion: The defining characteristics of peripheral vascular trauma generated a scientific theoretical structure for the nurses in their clinical practice, alerting them to the occurrence of this event in children.

Conclusion: The characterization of vascular trauma in children permits a re-evaluation of this procedure.

Descriptors: Nursing; Child; Nursing Diagnosis; Veins; Injuries.
\end{abstract}




\section{INTRODUCTION}

Technological developments, allied to better access to health services, have intensified the number of pediatric admissions due to acute disease, which can be incapacitating and complex, thus leading to the development of therapeutic approaches that are capable of prolonging survival and providing quality of care for the children, in addition to reducing their incapacitation ${ }^{(1,2)}$.

From the point-of-view of the use of blood vessels as a way of effecting the institutional care of the child, there has been an increased need to perform these invasive proceedings ${ }^{(1,3)}$. The peripheral venous puncture is an example of an invasive procedure, often performed in the treatment of hospitalized children ${ }^{(1)}$.

Such procedures are done with the aim of guaranteeing plasma levels and allowing the quick absorption of active treatments that ensure a quick recovery for the child, for example: to alleviate continuous or intensive pain; to administer treatments that by other routes would take longer; to respond to emergency situations with the desired effectiveness and to acquire samples for examination and diagnosis ${ }^{(3,4)}$. The use of blood vessels permits the administration of pharmacological, hemotherapeutic and immunologic therapies and the acquisition of samples for diagnosis ${ }^{(3,4)}$.

The task of assisting with peripheral vascular punctures is an inherent part of the daily work routine in nursing ${ }^{(3)}$. The process enables the vascular system to be accessed by a sequence of steps, starting from the preparation of the skin and selection of materials compatible to the user, up to caring for the skin after the removal of an intravascular catheter ${ }^{(5)}$. This process takes place in small clinics, homes and in large hospitals ${ }^{(3,4)}$.

In order to be able to puncture veins in children, the professionals performing this process need to acquire and develop certain abilities and technical, relational, cognitive, managerial and decision-making competencies, as this is a procedure that involves many participating factors ${ }^{(6)}$. Even with such abilities and competencies, nurses can find signs of iatrogenic trauma linked to peripheral venous puncture ${ }^{(5,7)}$. This is known as "peripheral vascular trauma" and originates from the insertion, maintenance and removal of catheters and from the infused or drained solutions/volumes.

To identify the iatrogenic trauma arising from the process of peripheral venous puncture in time to minimize it or treat it with therapeutic interventions (according to the qualifications of the nurse), the professional must base decisions on their knowledge regarding the conditions, circumstances and reasons that justified the use of the blood vessels and the profile and characteristics of the clientele whose veins have been punctured $^{(5,7)}$.

The existence of peculiarities in peripheral venous puncture in infants ${ }^{(6)}$ forces a rereading and a redesign of the procedure's paradigm, and the use of new technologies and understandings that will guarantee quality of service and safety to the child who will undergo venous puncture ${ }^{(6)}$.

The stage of development of the child at the time; the child's previous experiences; the type of interaction established between the child and parents/guardians and health professionals on the occasions when the blood vessels are punctured and the preconceived ideas the child has regarding how the puncture occurs and their experience of hospitalization - all these elements translate how children experience the puncture of their blood vessels $s^{(1,6,8,9)}$.

The inclusion of the nursing diagnosis of the "risk of vascular trauma" in the taxonomy of the North American Nursing Diagnosis Association (NANDA) demonstrates the proximity between the practice of the nurse and the use 
of technology, materials and knowledge related to venous puncture ${ }^{(5)}$. However, the process of venous puncture in children, full of peculiarities as it is, has become an specific area of work for pediatric nurses, which poses a new challenge ${ }^{(5)}$.

The object under investigation in this study is the clinical evidence of peripheral vascular trauma in children aged from six months to twelve years old, which is justified by the existence of a gap in the approach to the process of peripheral vascular puncture in children.

In this research, the nursing diagnosis of "peripheral vascular trauma" is generated when the individual presents with "internal or external damage in one or more layers of blood vessels, due to chemical, physical or biological origins, caused by a direct or indirect lesion on the vessels"(5). Based on what we discover, we aim to identify and document the clinical evidence and define the characteristics of peripheral vascular trauma in infants.

\section{METHOD}

This research was conducted using a survey $^{(10)}$ performed in the pediatric ward of a philanthropic hospital located at the Zona da Mata Mineira region, covenant to the Brazilian Unified Health System (SUS, in Portuguese) and to a private network of health insurance companies.

The sample population is composed of children who had their peripheral blood vessels punctured during the period of data collection. The eligibility criteria were: 1) children between six months and twelve years old; 2 ) children whose peripheral blood vessels were punctured for the first time at each site; 3 ) those children whose parents or guardians authorized the participation of the child in this investigation and allowed the researchers to take pictures of the manifestations of vascular trauma; 4) the volun- tary and non-funded participation of the child, as declared through the signature of the Free and Clear Consent Agreement, by their parents or guardians; 5) sites of insertion of catheters that could be evaluated after an interval no longer than 24 hours after puncture and followed up by daily clinic evaluation within a similar period and 6) access to the content of the multi-professional records in the child's medical record, including the process of the blood vessel puncture.

The puncture sites were monitored until: 1) 48 hours after the removal of the catheter, in cases where there was no evidence of peripheral vascular trauma or 2 ) the child was released for any reason or until 3) the total regression of the peripheral vascular trauma manifestations identified at the sites evaluated.

The criteria of exclusion were: 1) children whose parents/guardians did not authorize the participation of the minor in this investigation, or were not present during the investigation; 2) peripheral vessels that were punctured out of the period of data collection, or in sites previously punctured and 3) punctures with central catheters, of peripheral insertion.

Data collection occurred from January $8^{\text {th }}$ 2011 to May $9^{\text {th }} 2011$, a total of 122 consecutive days. During this stage, the researchers used an instrument of data collection previously validated in adults, in the elderly ${ }^{(5)}$ and in children ${ }^{(6)}$, which allows the triangulation of techniques to perform data collection, namely: clinical examination (inspection, palpation and measuring), interview (interaction) and photographic registry. This means that, during the period of data collection, these techniques were used daily to identify the occurrence of clinical evidence (the defining characteristics) of peripheral vascular trauma.

The variables that described the occurrence of peripheral vascular trauma were: alterations in skin color (hematoma, ecchymosis and erythema); alterations in skin integrity (edema, vesicles, 
induration and solution of continuity); increased pain sensibility; alteration in local temperature and limitation of functional capacity.

The measuring criteria adopted in this study included: 1) for edema: comparative measurement with the contralateral limb and a scale of $+/ 4+^{(11)}$; 2) for alterations in color: a chromatic pallet ${ }^{(6)}$ with local and contralateral comparative measurement; 3 ) for solution of continuity, vesicles and induration: measurement with a measuring tape ${ }^{(11)}$; 4) for temperature: palpation with the back of the hand comparing with the contralateral (search for a difference greater than $\left.\left.2^{\circ} \mathrm{C}\right)^{(5)} ; 5\right)$ for pain: analogic visual scale ${ }^{(12)}$ and 6) for functional capacity: a) a report from the child regards moving the punctured limb, gathered through the interaction (interview) between the researcher and the child and $b$ ) medical evaluation of the capacity of the child to move the limb, based on two scales, namely i) the Rossi and Mistrorigo scale with scores from 1 to 5 points, where a score of $1 / 5$ corresponds to minimal muscle power, or in other words, the child is not able to move the punctured body part against gravity, and where a score of $5 / 5$ is equivalent to normal muscle power, or in other words, the movements of the child are preserved and ii) the Robert Lovet scale with scores from 1 to 5 , where the interpretation is inverse to the Rossi and Mistrorigo scale ${ }^{(11)}$.

To consolidate and analyze the data, we used the Statistical Package for Social Science for Windows (SPSS) software. The exclusion criteria were applied in 39 cases: there was one denial to participate and sign the FCCA and 38 punctures were performed during a period longer than 24 hours before the first evaluation. Therefore, 338 samples of peripheral vascular sites were included in this study.

This project was submitted to the Committee of Ethics of the Holy House of Mercy of Juiz de Fora (Protocol 019/2010), thus following all ethical and legal requirements for research with children.

\section{RESULTS}

From the 338 sites of insertion of peripheral intravascular catheters evaluated, 216 (63.9\%) were in boys; 155 (45.8\%) were in children from six months to less than two years old; 105 (31.6\%) were in children from two to less than five years old; 78 (22.6\%) were in children from five to twelve years old and 221 (65.4\%) were in brown or black skinned children.

- Catheters, veins and place of insertion: The use of catheters with needles of flexible type, with mandrel and without extensors was unanimous, of which 319 (94.4\%) of the catheters were 24 Gauge $(\mathrm{G})$. The profiles of the punctured veins were: 321 (95\%) were of small caliber; 93 (27.5\%) were of tortuous caliber; 292 (86.4\%) were not palpable; 204 (60.4\%) were punctured outside of an articulation and 242 (71.6\%) were not visible.

The location of the punctures were: 1$)$ based on their location on the body: 173 (51.2\%) cases were on the back of the hand; 117 (34.6\%) cases were in the forearm; 46 (13.7\%) cases were in the lower limbs and 2 (0.6\%) cases were on the neck; 2 ) based on the roots of the punctured limb: 83 (24.6\%) cases were on the proximal third and $205(60.7 \%)$ cases were on the posterior side.

The average time of the use of the intravascular catheter was 2.7 days.

\section{- Recording of the punctures performed:}

The nursing records regarding the process of venous puncture (name of the professional that performed the puncture, date performed and location where the catheter was inserted) contained no information regarding the field where the catheter was inserted in 289 (85.5\%) cases, and this was sent to the patient's medical records without further documentation.

- Process of fixation of catheters and evaluation of local conditions:The number of 
adhesive strips used to hold the intravascular catheter varied from three to seven, of which $315(93.2 \%)$ cases were held by common adhesive plaster and 23 (6.8\%) cases used non-allergic adhesive plaster.

$105(31.1 \%)$ of the punctures presented some type of dirtiness, which means that there was some alteration to the original coloring of the adhesives, and in 39 (11.5\%) cases, some form of humidity was identified during the evaluation, reasons for which were: 16 (4.7\%) cases were moist due to contact with water; 11 (3.3\%) were moist due to the presence of intravascular solution and $5(1.5 \%)$ cases were moist due to contact with biological material, evidenced by traces of blood.

\section{- Types and occurrences of clinical evidence} of vascular trauma: In 180 (53.3\%) puncture sites, the presence of at least one clinical manifestation of vascular trauma was identified, as follows: 1) alteration of pain sensibility in $102(30.1 \%)$ cases, with an average score of 5 from a numeric scale of 0 to 10 , in which 10 represents the maximum level of pain; 2 ) reduction of functional capacity in 292 (86.4\%) cases, of which 271 (80.2\%) cases were identified by reports from the child, who mentioned difficulty in moving the body part that was punctured, and 21 (6.2\%) cases were identified by clinical evaluation by the professional, who observed partial or total limitation of the capacity to move the limb; 3 ) alteration of local body temperature in 48 (14.2\%) cases, of which 37 (10.9\%) cases were characterized by hypothermia and 11 (3.3\%) cases were characterized by hyperthermia and 4) alteration of skin integrity in 167 (47.7\%) cases, of which 129 (77.2\%) cases were characterized by the presence of edema (counted from +2 to +4$), 19(11.4 \%)$ cases displayed a rupture of the skin, $14(8.4 \%)$ cases were altered by the occurrence of induration and $5(3 \%)$ ca- ses were characterized by the presence of a vesicle/papule. There were 63 (18.6\%) cases of alteration of skin integrity accompanied by a change of skin color: 24 (38\%) of these with ecchymosis, 20 (31.8\%) with erythema and 19 (30.2\%) with hematoma.

The registers of clinical evidence of peripheral vascular trauma in children, documented in photos, are detailed in Image 1.

Image 1: Clinical evidence of peripheral vascular trauma. Juiz de Fora, Brazil, 2012.

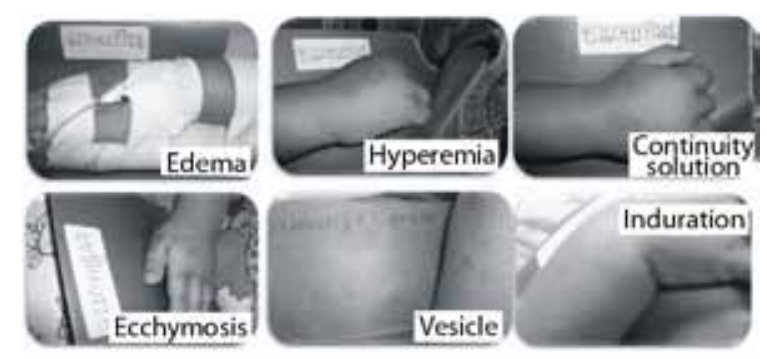

Source: Photographic records of Arreguy-Sena \& Avelar-Silva, 2012.

\section{DISCUSSION}

The comparative analysis of the hospitalization rates based on gender to the pediatric ward investigated, showed that less girls were hospitalized than boys. Such a fact can be explained, in part, by the higher number of infant accidents involving boys ${ }^{(13)}$.

When observing the age group of the children included in this study, it is possible to say that $71.9 \%$ of the venous punctures performed occurred in children aged from six months to less than four years old, i.e. children in a stage of physiologic maturation, or the pre-school stage $^{(2)}$. The stage of infant development has an effect on the interpretation given by the child to an external stimulus, such as the peripheral venous puncture ${ }^{(1,2,6)}$ :

Children in the first stage of infant development (birth to 18 months old), while exploring 
their physical space, develop interactional and communicational abilities and build links with people around themselves (with parents/relatives). In this sense, home is the favored location for the development of such abilities because it constitutes an environment where stimuli can be monitored and modeled by parents/relatives.

During hospitalization, familiarization with more people and the presence of therapeutic interventions are examples of stimuli foreign to the family model that take precedence over the development/responses of the child ${ }^{(2)}$. The presence of a tutor with the child during the time of hospitalization $^{(2)}$ is not always a sign of security to the child, since the accompanying people also experience the impacts of hospitalization of a under-age relative ${ }^{(1)}$. The novelties of the hospital environment, in these circumstances, do not guarantee the right environment and stable routine necessary for the development of the child during this stage.

During the second stage of infant development, the pre-school stage (from 18 months old to four years old), physical development is compatible with the initiatives of mobility, of expression and of the communication skills of the child, in order to assist their interaction with other children of the same age. In this sense, hospitalization and the performance of invasive proceedings, such as the peripheral vascular puncture, are interpreted as sources of stimulus that can generate a regression in infant development; they turn back because of the insecurity and fear generated by the inhospitable environment and the use of proceedings interpreted by the child as life threatening ${ }^{(1,2)}$.

Another factor that interferes in the process of development of the hospitalized child is the concessions given by the parents in order to bargain with the child, to give their child some support from the suffering and from dealing with the illness ${ }^{(1,2)}$. These concessions compro- mise the capacity of the child to interact, share and use symbols to express and communicate with tranquility ${ }^{(1,2)}$.

The analysis of the ethnicity of the children studied showed that a higher number of children of brown and black skins were hospitalized, both in the pediatric ward where this study took place, as well as in the whole city: $65.4 \%$ and $71 \%$, respectively ${ }^{(14)}$.

- Catheters, veins and place of insertion: The analysis of the type of peripheral intravascular catheter used showed that the identification of the advantages and disadvantages of each piece of equipment used in performing venous puncture on a certain population segment is an everyday part of the nurses' decision-making processes. The characterization of the veins punctured, analyzed using the set of classification criteria ${ }^{(5,7)}$, revealed that the peripheral vascular puncture process in children has some specificities, such as the small caliber and the non-visibility of the veins. The ability of the professional performing the procedure, based on these peculiarities, is supported by a strategy that is capable of providing an adequate choice/selection of materials, in order to allow them to meet the individual needs of their patients. One good example is the provision of materials that contribute to the successful cannulation of the blood vessels ${ }^{(1,15)}$, which reduces the number of attempted punctures and minimizes the occurrence of peripheral vascular trauma ${ }^{(1,5)}$.

- Recording of the punctures performed:The maintenance of nursing records is mandatory and the analysis ${ }^{(16)}$ of the events enabled the researchers to observe that the nursing team, during the evaluation period, did not follow the legal requirements, according to the Resolution 358/2009 of the Brazilian Federal Council of Nursing (COFEn, in Portuguese) ${ }^{(16)}$. The records are instruments used by the nursing 
professionals to guide and communicate with other members of the team and to ensure the sharing of information, in regards to how the vessel puncturing process was performed ${ }^{(16)}$.

- Process of fixation of catheters and evaluation of local conditions: The analysis of the process of fixation showed an elevated number of fixation adhesive strips and the predominant use of common adhesive plaster. This fact is against the consensus for using sterile transparent covers, which enables daily follow-up inspections and reduces patient exposure to pathogens, humidity and foreign dirt ${ }^{(4)}$.

The presence of dirt and humidity at the site of insertion and/or in the surroundings of peripheral catheters can be related to the fact that more than $50 \%$ of the punctures performed were situated on the hand of the child and to the fact that children take their hands to their mouths frequently ${ }^{(2)}$.

\section{- Types and occurrences of clinical evidence} of vascular trauma: Of the 338 peripheral vascular punctures studied 180 (53.3\%) had at least one of the five clinical manifestations that the researchers used as evidence to identify the types of "peripheral vascular trauma" in children between six months and twelve years old.

Among the changes in skin color, there was hematoma, ecchymosis and erythema. The hematoma and ecchymosis originated from the leakage and subsequent accumulation of blood in the interstitial spaces, which could later develop into an infection because the blood is a culture environment for microorganisms ${ }^{(17)}$.

The mechanism of the formation of an hematoma or an ecchymosis is that there is an initial accumulation of blood outside of the vessel ${ }^{(17)}$. Macrophages work in the phagocytosis of red blood cells located in the extracellular space, in an activity where the hemoglobin is reduced by hemosiderin and porphyrin, which are chestnut-brown and purple pigments, res- pectively ${ }^{(17)}$. This evidence can occur because of damage to the blood vessel ${ }^{(5)}$, removal of the IV catheter before the removal of the tourniquet and non-compression of the site of insertion of the catheter after its removal until final local coagulation has occurred ${ }^{(5,7)}$. These lesions are included in the characteristics of peripheral vascular trauma previously mentioned in this study.

In the case of erythema, the reddish color is due to a higher intake of blood and, in consequence, there is a reactive hyperthermia (with the expansion of the arterioles) ${ }^{(17)}$. In other wor$\mathrm{ds}$, the rise in tissue activity causes the cells to consume more nutrients and then the vessels expand to supply the local demand for oxygen ${ }^{(17)}$.

Among the manifestations of vascular trauma that generate an alteration to skin integrity, the researchers found edema, induration, the formation of vesicles/papules and the solution of continuity.

Among the possible causes of the edema, linked to the process of vascular puncture, are the overflow of infused/drained/accumulated volumes in the extravascular space (intracellular or extracellular) $)^{(5)}$.

The overflow of liquids to the intracellular space can originate from an inflammatory process (reactions to the components of the catheter), from an infectious process (collection of pus) ${ }^{(5)}$ or from damage to the vessels during catheterization ${ }^{(5)}$. When this process occurs, the cellular permeability is increased, which helps the intake of sodium and other ions to the interior of the cell, triggering the process of osmosis and, as a consequence, edema ${ }^{(5)}$.

In the case of edema of extracellular origin, damage to the blood vessels leads to the overflow of blood into the interstices until the process of coagulation is activated, when the overflow of plasma continues until the conclusion of this later process, causing edema ${ }^{(5)}$. 
Another manifestation of trauma is induration. This manifestation is characterized by cellular thickening, observed by the hardening of the area around the site of insertion of the peripheral IV catheter, or above the vessel itself. In this case, the secondary edema in the cellular prominence and the dilation of the pores gives the skin an appearance of "orange peel"(5). Among the causes of induration are the contact of the needle with the intima (local manifestations) or the thickening of the intima due to the $\mathrm{pH} /$ concentration of solutions infused (track manifestations $)^{(5)}$. In both cases, the occurrence of induration is due to the outbreak of an inflammatory reaction ${ }^{(5)}$.

The papules and/or vesicles are solid lesions identified in manifestations of vascular trauma that have a hardened consistency and are circumscribed, small (less than $5 \mathrm{~mm}$ ) and raised ${ }^{(5,17)}$. They are caused by the accumulation of cells, which could be caused by an allergic reaction ${ }^{(5)}$. The occurrence of papules and/or vesicles in the process of peripheral vascular puncture can occur, for example, by the initiation of an allergic reaction to the adhesive plaster.

The solution of continuity occurs with the insertion of the IV catheter, when piercing the corneous strata of the blood vessel ${ }^{(5)}$, which causes a rupture of the cutaneous integrity; this is a serious issue for the nursing staff, because this lesion makes the child more vulnerable to the possibility of the displacement and/or introduction of germs from the local area ${ }^{(5)}$. This fact is reported in NANDA's taxonomy under the heading "Risks of infection" related to invasive proceedings $^{(18)}$.

The basis of preventing such risks is keeping the site of insertion of intravascular catheters dry, clean and in contact with sterile material, until the formation of a healing epithelial bridge, as it is necessary for the equipment to be inserted into the blood vessel for therapeutic purposes"(5).
Trauma is also accompanied by alterations in the temperature of the local area surrounding the insertion of the peripheral intravascular catheter. Body temperature is a vital sign, providing objective data that shows the state of health of an individual. There are two temperatures that regulate the human body: central and cutaneous ${ }^{(11)}$.

Central temperature is related to the deep tissues of the body and is constant, at around $0.6^{\circ} \mathrm{C}$, even when a naked individual is submitted to external temperatures varying from $13^{\circ} \mathrm{C}$ to $60^{\circ} \mathrm{C}^{(11)}$. The cutaneous temperature can increase or decrease according to the external temperature and, therefore, it is a temperature that oscillates considerably when compared to central temperature ${ }^{(11)}$.

Following peripheral vascular puncture, the evaluation of cutaneous temperature at the site of insertion of an IV catheter, and the surrounding area, is a mechanism for detecting the occurrence of one of the manifestations of vascular trauma. An alteration in temperature at the puncture site, when compared to the equivalent contralateral body part, excluding systemic alterations of body temperature, can signal the beginning of vascular trauma ${ }^{(5)}$.

Considering that cutaneous temperature is influenced by environmental temperature ${ }^{(11)}$, it was necessary to analyze the alteration in temperature between the site of insertion and the surrounding area as part of this research. There was an expectation that the research would find a higher number of cases of hyperthermia, when considering the environmental effect on temperature at the puncture site. However, the results showed the occurrence of hypothermia in $37 \%$ of cases and hyperthermia in $11 \%$, which means that the findings showed the opposite of that expected.

If, on the one hand, one of the factors generating the hypothermia is the characteristically 
colder temperature of the intravascular solutions infused when compared to body temperature, on the other hand, in order to explain the cases of hyperthermia (11\%), temperature needs to be analyzed alongside any alterations to skin color (18.6\%) and the occurrence of erythema (5.9\%), which are symptoms that signal the initiation of peripheral vascular trauma as a consequence of inflammatory and/or infectious processes ${ }^{(5)}$.

The detection of peripheral vascular trauma by the alteration in functional capacity was evaluated according to the reports of the children of partial or total limitation of movement in the punctured limb, as well as by the clinic evaluation of the researcher regarding the limitation observed. The measurement of the occurrence of this clinical manifestation was contradictory, with $80.2 \%$ arising from reports from the child and only $6.2 \%$ arising from professional clinic evaluation. This fact can be explained by one specific factor in the process of peripheral vascular puncture when performed in children ${ }^{(6)}$. Feelings of threat, based on the imminence of a new vessel puncture (anguish, sadness and fear) $(1,19)$ explains why the children investigated were not able to move the punctured limbs when compared to the clinic analysis of movement restriction.

Pain, another clinical symptom of vascular trauma, is defined by a subjective experiment, as an unpleasing sensation ${ }^{(6)}$, associated with real or potential damage to the tissues. The frequency with which pain was reported in this research can be considered as a specific factor of the age of the subjects, when compared to the evaluation of this same phenomenon among adults or in the elderly ${ }^{(5)}$.

The way this procedure is experienced by the children, and the way it is approached by the professionals, requires therapeutic monitoring and an approach closer to a scientific spectrum ${ }^{(1)}$. How it is approached represents an opportunity to minimize iatrogenic trauma, to reduce the child's exposure to stress and to assist and consolidate the development of adaptive mechanisms that are indispensable to healthy development ${ }^{(1,20)}$.

Considering the subjective nature of pain and the peculiarity of the stages of development throughout childhood, the individual perception of pain, or pain sensibility, expressed by the infantile subjects is based on specifics such as: personality, cognitive aspects, behavioral manifestations and socio-environmental context.

The personality, as a set of psychological characteristics, influences the ways of thinking, feeling and acting, which are expressed by the individuality of the child ${ }^{(1)}$. It explains the different perceptions of pain, even in children within the same age group ${ }^{(1)}$.

Depending on how the child experiences and interprets pain and on the predominant determining factors (personal, social or relational), how the child will face any given situation will be a more or less remarkable experience. This can be understood by the fact that the child's reaction to pain manifests with more or less intensity, with the presence of aggression or dullness, the use of cursing or bargaining, expressions of fighting or shouting, or with a sense of feeling cornered or behaving passively towards the "power" the child sees in the health team and/ or parents, acting against the child's will.

The fact that children are still developing (physically, neurologically, cognitively and behaviorally) explains their immaturity in reacting to new experiences, for example, peripheral vascular puncture ${ }^{(1)}$. Children frequently display instability in the way they react to, think about and perceive this experience ${ }^{(1)}$.

The consolidation of a favorable behavior only emerges after many experiences, when the children will have had the opportunity to experiment with many different behavior patterns, 
until they find one appropriate to positively face the situation experienced ${ }^{(1)}$.

During the identification of the occurrence of the different types of clinical manifestations observed in children aged six months to twelve years old, it was possible to identify that some of these happened in combination with another manifestations; in other words, there was some concomitance. One example is a rise in local body temperature, followed by erythema and/or pain. Such facts lead to the following question: are those defining characteristics happening simultaneously or sequentially? The answer to this question can alert the nurse to make an early identification of the first manifestations of trauma, avoiding the progression of the trauma by starting, in a timely manner, therapeutic treatments to minimize the problem.

The fact that the manifestations of peripheral vascular trauma arise as a consequence of the presence of a catheter, or from the type of infused solution and/or the overflowing of infused/drained fluids ${ }^{(5,6)}$ means that these manifestations cannot always be prevented. Trauma should be avoided whenever possible but where peripheral vascular puncture is unavoidable and there is a risk, or diagnosis, of vascular trauma, this can be minimized or treated by the use of good nursing routines.

\section{CONCLUSION}

When evaluating, on a daily basis, the sites of peripheral vascular punctures and the areas surrounding these punctures, it was possible to identify five types of clinical evidence, which are the defining manifestations of "peripheral vascular trauma", in children aged six months to twelve years old.

The techniques of data collection permitted the researchers to quantify and identify the types of trauma that occurred during the process of venous puncture in children. They were identified as: 1) alterations in skin color, identified as hematoma, ecchymosis and erythema; 2) alterations in skin integrity, identified as edema, induration, vesicles and solutions of continuity; 3) alteration in local temperature; 4) alteration in functional capacity and 5) alteration in pain sensibility. These manifestations occurred individually or in concomitance with each other.

The presence of at least one of the clinical manifestations previously mentioned, when linked to the process of vascular puncture, was evidence, from the conceptual point-of-view, confirming the presence of peripheral vascular trauma ${ }^{(5)}$. In this sense, this investigation contributed to identifying the types of trauma and the specificities of the process of peripheral vascular puncture in an infant population aged six months to twelve years old.

Such a contribution is an alert to the nurses regarding the necessity of them adjusting their conduct and reviewing the demands of nursing care during the whole process of vascular puncture. The quality of service and the physical, emotional, social, psychological and moral safety of the children that undergo vascular puncture must be ensured.

The process of peripheral vascular puncture can result in many clinical manifestations of trauma, from which emerged the following question: which is the initial manifestation of peripheral vascular trauma, the observation of which would assist the nurse in diagnosing the occurrence of vascular trauma and, therefore, allow the process to be stopped while in the early stages?

Based on what has been exposed here, we recommend the development of a recording protocol for the process of vascular puncture in the child's medical records and a secondary record (installation date, change of adhesive and 
caliber of catheter) on the fixing adhesive, in a way that will not impede visualization of the site of insertion of the catheter.

\section{REFERENCES}

1. Gary AW. Needle Pain in Children: Contextual Factors. Pediatrics. 2008;122 Suppl 2: 125-9.

2. Hockenberry MJ, Wilson DW. Fundamentos de Enfermagem Pediátrica. 8. ed. São Paulo:Elsevier; 2011.

3. Adams J, Aguiar T, Bierman S, Bishop C, Blackburn P, Bonilla B. Infusion Nursing Standards of Practice. Norwood: Infusion Nurses Society; 2011.

4. Grady NPO, Alexander M, Burns LA, Dellinger P, Garland J, Hard SO, et al. Guidelines for the Prevention of Intravascular Catheter-related Infections. Atlanta: Centers for Disease Control and Prevention; 2011.

5. Arreguy-Sena C, Carvalho EC. Risco para Trauma vascular: proposta do diagnóstico e validação por peritos. Rev bras enferm. 2009; 62(1): 71-8.

6. Silva RNA. Validação Cínica do Diagnóstico"Trauma Vascular Periférico"em Crianças de 6 meses a 12 anos [dissertação]. Juiz de Fora: Universidade Federal de Juiz de Fora; 2012.

7. Arreguy-Sena C, Carvalho ECd. Superficial peripheral vein type classification of adolescents, adults and elderly according to the Delphi technique. Rev latinoam enferm. 2008;16(1):86-94.

8. Daniel R. Peripheral Difficult Venous Access in Children. Clin Pediatr. 2009;48(9):895-901.

9. Liam M. The Association Between Parent's and Healthcare Professional's Behavior and Children's Coping and Distress During Venepuncture. J Pediatr Psychol. 2010; 35 (9): 985-95.

10. Medronho RA, Bloch KV, Wernech GL. Epidemiologia. 2. ed. São Paulo: Atheneu; 2009.

11. Guyton AC, Hall JE. Guyton \& Hall Tratado de Fisiologia Médica. 12. ed. Rio de Janeiro: Elsevier; 2012.

12. Pinto PF, Fernandes AA, Botelho MAS. Escada Visual Analógica: coleta de dados em saúde e em atividade física. Rev Soc Cardiol Estado de São Paulo. 2008; 18(2):182.
13. Briccius M, Murofuse NT. Atendimento de crianças realizado pelo SIATE de Cascavel no ano de 2004. internet: Revista Eletrônica de Enfermagem. 2008; 10(1):152-66.

14. Ministério da Saúde (Brasil) [Homepage on the internet]. CIHA - Comunicação de Informação Hospitalar e Ambulatorial [Cited 2011 Setembro 18]. Available from: http://ciha.datasus.gov.br/ $\mathrm{ClHA} /$ index.php?area $=01$.

15. Hosokawa K, Kato H, Kishi C, Kato Y, Sime N. Transilluminationby light-emitting diode facilitates peripheral venous cannulations in infants and small children. Acta Anaesthesiol Scand. 2010; 54(8): 957-61.

16. Conselho Federal de enfermagem (Brasil). Resolução no 358, de 15 de outubro de 2009. Dispõe sobre a Sistematização da Assistência de Enfermagem e a implementação do Processo de Enfermagem em ambientes, públicos ou privados, em que ocorre o cuidado profissional de Enfermagem. Diário Oficial da União 23 out 2009.

17. David AR, Rubem AD, Luna A-A. Dermatologia. 5. ed. Rio de Janeiro: Guanabara Koogan; 2011.

18. NANDA International. Nursing Diagnoses: Definitions and Classification 2012-2014. lowa: Wiley-Blackwell; 2012.

19. Bezerra P, Nóbrega M. NANDA-I nursing diagnosis in hospitalized children: a case study. Online braz j nurs [Internet]. 2012 [Cited 2012 Jul 16]; 11(1). Available from: http://www.objnursing.uff.br/ index.php/nursing/article/view/3553.

20. Brasil. Lei no. 8069, de 13 de julho de 1990. Dispõe sobre o Estatuto da Criança e do Adolescente e dá outras providências. Diário Oficial da União 16 jul 1990. Seção 1.

Authors

Raquel Nogueira Avelar e Silva - participated in all stages of the research (data collection, writing, review, final writing). Cristina Arreguy-Sena - participated in writing, review and final writing.

Received: 31/07/2012

Revised: $18 / 02 / 2013$

Approved: 08/04/2013 